\title{
J R H Ross (ed): Heterogeneous Catalysis: Fundamentals and Applications
}

\author{
Elsevier, Amsterdam, 2012, Hardback, 232 p, \$155, ISBN 978-0-444-53363-0
}

\author{
Michael Bowker
}

Received: 24 July 2012/Accepted: 24 July 2012/Published online: 10 August 2012

(C) Springer Science+Business Media, LLC 2012

\section{Book Review: Ross "Heterogeneous Catalysis"}

This book covers the theme of heterogeneous catalysis in a very readable style within a beautifully laid-out, uncluttered presentation format. Though not clearly stated in the preface, it appears to be aimed at an undergraduate audience, but is also appropriate as one source of material for a specialist masters course or for beginning $\mathrm{PhDs}$ without much knowledge of catalysis. It is a basic text without a lot of detail on any particular topic, restricted by the limited size of the book-it is 217 pages, and is extremely expensive ( $\$ 150$ hardback) considering the content. Although there are a number of books out there on the subject of heterogeneous catalysis, it is a most important field of endeavour for research, current technology and for the advancement of mankind, especially in the way it uses natural resources, and so this book adds to our library of information on the subject.

Chapters cover a variety of topics in an attempt to encompass the field-such as the historical development of heterogeneous catalysis, surfaces and adsorption, catalyst preparation, reactor types and some specific industrial reactions. In many ways it covers the same well-trodden ground of a number of other books on this subject, though the chapters on reactor configurations and diffusion limitations are a welcome addition to such a basic book on the subject. It appears from much of the text that the author feels that the subject has not advanced significantly in the last 50 years or so, since the literature citations are generally very old. By way of compensation, the author has endeavoured to steer the reader forward in time by suggesting they "work forward" via search engines. There are also "task" boxes throughout the book, which often simply direct readers to the web to find more information related to particular topics, sometimes in an apparently trivial way. It would have been useful to introduce some of the important advances in our understanding of catalysis which have occurred in the last decades-for instance, the effect of surface structure on reactivity, which is profound, and which, combined with computer modelling, will become the basis of industrial catalyst design in the coming decades. On the other hand, in several places we are usefully reminded that some old, forgotten topics have re-emerged as 'hot' in recent times. There are excellent introductory chapters on reactors (both large and small scale versions), and some of the currently important industrial catalytic reactions are covered, together with some emerging fields, such as biomass conversion.

In summary, this is a useful addition to the bookshelf of a practitioner in catalysis, to academic libraries, and as a basic guide for students, and as such is to be recommended alongside a number of other texts. 